\title{
Effects of therapeutic Tai chi on functional fitness and activities of daily living in patients with Parkinson disease
}

\author{
Hye-Jung Choi* \\ Department of Physical Therapy, College of Science, Ansan University, Ansan, Korea
}

The purpose of the study is to investigate the effects of therapeutic Tai chi (TTC) on the functional fitness status and activities of daily living (ADL) of patients with Parkinson disease (PD). The participants were clinically stable PDs in Hoehn and Yahr stage 1-2. These patients were randomly assigned to either the $\Pi \mathrm{TC}$ group $(n=11)$ or the control (CON) group $(n=9)$. The TTC exercised at the clinic 2 times a week and performed home-based activity 1 time per week for 12 weeks. All the PDs were evaluated for functional fitness test and ADL screen before and after the 12-week trial. There was a significant Time $\times$ group interaction effect on the arm curl $(P<0.01)$, functional reach $(P<0.05)$, and stand on foot with eyes opened $(P<0.05)$ of the functional fitness as compared to the CON. The results of the functional reach test in the CON worsened significantly during the 12-week intervention in comparison with those of the TTC $(P<0.01)$. Also ADL showed significant changed in TCC $(P<0.05)$. Tai chi training showed good effects on the functional fitness in PDs. This study suggests that further research into the based such as Tai chi intervention must be developed PD's quality of life in the future.

Keywords: Parkinson disease, Tai chi, Functional fitness, Activities of daily living

\section{INTRODUCTION}

Disease-matched clinical exercise programs are very important strategies for treating patients with Parkinson disease (PD) (Burini et al., 2006). Traditional rehabilitation interventions have focused on physical and occupational therapy to help maintain a higher functional status (De Goede et al., 2001). Only a few such studies have shown that exercise programs are effective for improving the impaired functions of PDs (Goodwin et al., 2008). Tai chi is a traditional Chinese martial art that involves slow and graceful movements that can improve postural balance, flexibility, and mood (Choi et al., 2013; Fong and Ng, 2006). Recently, Tai chi has been found to exert a positive influence on the clinical treatment of the physical activity, fatigue, and the quality of life of patients with advanced cancer and neurodegenerative disease, as well as el- derly people with chronic pain (Lan et al.,1996; Xu et al., 2005; Zhang et al., 2006). Exercise interventions for PDs should include physical and psychological intervention, because most PDs have limited function, general fatigue, depression, and a negative quality of life. The prevalence of depression among PDs ranges from $20 \%$ to $70 \%$ (Ehrt et al., 2006). A study noted improvement of rigidity and motor function with the use of behavioral therapy for anxiety, and the subjects showed improved emotional states (Carlson, 2005).

The current study is focused on therapeutic Tai chi (TTC) for PDs, which combines deep breathing, meditation, and slow movement with postural stability. The purpose of this study is to investigate the effects of TTC training on improving the functional fitness status and activities of daily living (ADL) of PDs for their health-related quality of life.

\footnotetext{
${ }^{*}$ Corresponding author: Hye-Jung Choi (i) http://orcid.org/0000-0002-8989-1510 Department of Physical Therapy, College of Science, Ansan University, 155, Ansandaehak-ro, Sangnok-gu, Ansan 15328, Korea Tel: +82-31-363-4462, Fax: +82-31-363-4465, E-mail: hjchoi@ansan.ac.kr Received: June 9, 2016 / Accepted: September 5, 2016
}

This is an Open Access article distributed under the terms of the Creative Commons Attribution Non-Commercial License (http://creativecommons.org/licenses/by-nc/4.0/) which permits unrestricted non-commercial use, distribution, and reproduction in any medium, provided the original work is properly cited. 
Table 1. Characteristics of the study participants

\begin{tabular}{lrrc} 
Variable & $\begin{array}{c}\text { Therapeutic Tai chi } \\
(\mathrm{n}=11)\end{array}$ & $\begin{array}{c}\text { Control } \\
(\mathrm{n}=9)\end{array}$ & P-value \\
\hline Age $(\mathrm{yr})$ & $60.81 \pm 7.6$ & $65.54 \pm 6.8$ & $\mathrm{NS}$ \\
Body mass index $\left(\mathrm{kg} / \mathrm{m}^{2}\right)$ & $24.93 \pm 3.7$ & $25.41 \pm 3.0$ & $\mathrm{NS}$ \\
Years since diagnosis & $5.2 \pm 2.7$ & $5.2 \pm 2.7$ & $\mathrm{NS}$ \\
Hoehn-Yahr stage & $1.6 \pm 0.6$ & $1.8 \pm 0.3$ & $\mathrm{NS}$ \\
\hline
\end{tabular}

Values are presented as mean \pm standard deviation.

NS, not significant.

\section{MATERIALIS AND METHODS}

\section{Participations}

The participants of this study were clinically stable patients with diagnosed idiopathic PD recruited from the Parkinson's Disease Center in Asan Medical Center in Seoul, Korea. Eligible participants met the following inclusion criteria: (a) Hoehn-Yahr stage 1 or 2, and (b) stable drug regimen. Participants were randomized to either a 12-week intervention of TTC or a nonexercise control group. The TTC group visited the clinic 2 times a week and performed home-based activity 1 time per a week for 12 weeks. Characteristics of the participations is shown in Table 1.

\section{Experimental procedures}

\section{Tai-chi exercise program}

The Tai chi program is outlined in Table 2. Each TTC session started with a 10-min stretching exercise warm up, followed by $30 \mathrm{~min}$ of Tai Chi exercises, and ending with $10 \mathrm{~min}$ of meditation and 10 min of stretching exercise cool-down. The TTC was performed within the intensity ranges of 11 to 15 (light to somewhat hard) on the Borg Ratings of Perceived Exertion Scale (American College of Sports Medicine, 2010). Study outcome measures were obtained at baseline (prerandomization; one week prior to the start of the program) and within one week following the end of the 12-week intervention.

\section{Functional fitness test and ADL evaluation}

The outcome measures included several tests of physical fitness based on the method of Rikli and Jones (1999). ADL was measured using Unified Parkinson's Disease Rating Scale-III (UPDRS). The evaluator was blinded to the participant's intervention group assignment. To assess upper body strength, the number of bicep curls that a patient could complete in 30 sec holding a hand weight of $2.26 \mathrm{~kg}$ for women and $3.62 \mathrm{~kg}$ for men was counted. Standing-up and sitting-down from a chair was used to assess
Table 2. Therapeutic Tai chi exercise program

\begin{tabular}{|c|c|}
\hline Week & Therapeutic Tai chi exercise \\
\hline 1 & Orientation, Basic stretching \\
\hline 2 & Abdominal breathing, Neck \& shoulder movement exercise \\
\hline 3 & Abdominal breathing, Trunk, hip, knee and ankle movement exercise \\
\hline 4 & Abdominal breathing, Summary of Tai chi warm-up, Relaxation \\
\hline 5 & $\begin{array}{l}\text { Abdominal breathing } \\
\text { T1. Commencing movement } \\
\text { T2. Opening \& closing hands } \\
\text { T3. Single whip }\end{array}$ \\
\hline 6 & $\begin{array}{l}\text { Abdominal breathing } \\
\text { T4. Waving hands in the cloud } \\
\text { T5. Closing movement }\end{array}$ \\
\hline 7 & $\begin{array}{l}\text { Abdominal breathing } \\
\text { Review and practice }\end{array}$ \\
\hline 8 & $\begin{array}{l}\text { Abdominal breathing } \\
\text { T6. Brush knee } \\
\text { T7. Playing lute }\end{array}$ \\
\hline 9 & $\begin{array}{l}\text { Abdominal breathing } \\
\text { T8. Perry and punch }\end{array}$ \\
\hline 10 & $\begin{array}{l}\text { Abdominal breathing } \\
\text { T9. Block } \\
\text { T10. Opening \& closing }\end{array}$ \\
\hline 11 & Review and practice \\
\hline 12 & Review and practice \\
\hline
\end{tabular}

lower body strength. The number of full stands that a participant could complete in $30 \mathrm{sec}$. For the timed up and go test, the participants were seated in an arm-chair with their backs against the chair. On an auditory signal, they stood up, walked $3 \mathrm{~m}$ as quickly and safely as possible, then turned around, walked back to the chair. The score was the time to completion. The functional reach test measures the ability to reach forward from a bilateral stance position. The arm closest to the wall is raised to shoulder height, and the position of the knuckle of the middle finger is measured. Standing on one foot with eyes opened is a measure of balance and functional mobility. The participants stood with hands on hips with eyes opened. The test score was the total time standing on one leg. The 6-min walk test was applied as a test of cardiorespiratory endurance for daily physical activities.

\section{Statistical analyses}

Descriptive results were expressed as means and standard deviations. An analysis of variance for repeated-measures with one between factor (TTC vs. CON) and one within factor (time; preand postintervention) was used to evaluate the effects of the intervention. Significance levels were set $a$ priori at $P \leq 0.05$. All analyses were conducted using IBM SPSS ver. 18.0 (IBM Co., Armonk, NY, USA). 
Table 3. Functional fitness before and after 12-week therapeutic Tai chi exercise

\begin{tabular}{|c|c|c|c|c|c|c|c|}
\hline \multirow{2}{*}{ Variable } & \multicolumn{2}{|c|}{ TाC } & \multicolumn{2}{|c|}{ Control } & \multicolumn{3}{|c|}{$P$-value } \\
\hline & Pre & Post & Pre & Post & $\operatorname{Time}^{\mathrm{a})}$ & Group ${ }^{\text {b) }}$ & Time $\times$ group \\
\hline Arm-curl (rep/30 sec) & $16.00 \pm 4.24$ & $18.09 \pm 2.42$ & $17.33 \pm 4.71$ & $14.33 \pm 3.80$ & 0.614 & 0.425 & $0.010^{*}$ \\
\hline Stand-up and sit-down from a chair (rep/30 sec) & $11.91 \pm 3.59$ & $12.27 \pm 2.79$ & $12.44 \pm 2.96$ & $10.67 \pm 5.59$ & 0.320 & 0.738 & 0.139 \\
\hline Timed up and go (sec) & $7.39 \pm 0.89$ & $7.03 \pm 0.90$ & $8.06 \pm 2.91$ & $9.32 \pm 4.16$ & 0.294 & 0.173 & 0.066 \\
\hline Functional reach (cm) & $29.95 \pm 5.8$ & $28.18 \pm 6.28$ & $31.22 \pm 7.87$ & $25.50 \pm 6.43$ & $0.003^{*}$ & 0.800 & 0.091 \\
\hline Stand on foot with eyes opened (sec) & $3.34 \pm 3.01$ & $5.91 \pm 4.22$ & $3.77 \pm 2.43$ & $2.66 \pm 1.89$ & 0.378 & 0.229 & $0.035^{*}$ \\
\hline 6-min walk (m) & $442.57 \pm 71.65$ & $472.05 \pm 58.63$ & $369.92 \pm 139.71$ & $368.56 \pm 152.55$ & 0.284 & 0.079 & 0.241 \\
\hline
\end{tabular}

Values are presented as mean \pm standard deviation.

$\Pi \mathrm{TC}$, therapeutic Tai chi.

${ }^{*} P<0.05$. ${ }^{\text {alPre vs. Post. }}{ }^{\mathrm{b}} \mathrm{T} T \mathrm{C}$ vs. control.

Table 4. Changes on the ADL after 12 weeks of Tai chi exercise

\begin{tabular}{|c|c|c|c|c|c|c|c|}
\hline \multirow{2}{*}{ Variable } & \multicolumn{2}{|c|}{ TाC } & \multicolumn{2}{|c|}{ Control } & \multicolumn{3}{|c|}{$P$-value } \\
\hline & Pre & Post & Pre & Post & Time $e^{a l}$ & Group ${ }^{b)}$ & Time $\times$ group \\
\hline ADL & $7.91 \pm 1.81$ & $5.82 \pm 3.37$ & $7.89 \pm 3.62$ & $8.22 \pm 3.70$ & 0.119 & 0.378 & $0.037^{*}$ \\
\hline
\end{tabular}

Values are presented as mean \pm standard deviation.

ADL, activities of daily living; $T T C$, therapeutic Tai chi.

${ }^{*} P<0.05$. ${ }^{\text {alPre vs. Post. }}{ }^{\mathrm{b}} \mathrm{TTC}$ vs. control.

\section{RESULTS}

\section{Changing of functional fitness status}

The changes of the functional fitness following the 12-week TTC in the PDs are shown in Table 3. On such tests as arm curls $(P<0.01)$, functional reach $(P<0.05)$, and standing on one foot with eyes opened $(P<0.05)$, there were significant differences between the two groups in terms of the before and after effects of the interaction. The results of the functional reach test in the CON worsened significantly during the 12 -week intervention $(P<$ 0.01). Other physical fitness, including standing-up and sitting-down, sit and reach, and 6-min walk showed no statistical significance despite that the training group showed a slight improvement following the training.

\section{Changing of ADL}

The changes of ADL using UPDRS following 12 weeks of TTC training in the PDs are shown in Table 4. There was a significant interaction between the time and group on the TCC $(P<0.05)$.

\section{DISCUSSION}

In the present study, we investigated the functional fitness and ADL of PDs after they underwent TTC exercise intervention. Physical fitness in our study was evaluated by arm-curl, stand-up and sit-down from a chair, timed up and go, functional reach, sit and reach, stand on foot with eyes opened, and 6-min walk. Armcurl test results showed that the upper muscle strength was considerably increased after 12 weeks of exercise training. Generally, Tai chi exercise training has been shown to increase upper and lower body muscular strength and improved knee joint proprioception (Tsang and Hui-chan, 2004). The results of the standing-up and sitting-down test of the lower muscle strength in the CON worsened during the 12-week intervention. TTC training has benefits for lower body strength and postural stability in PDs by acting on a number of knee joint proprioception sensorimotor systems that contribute to postural control (Xu et al., 2005). The timed up and go test showed that the TTC was much faster than the $\mathrm{CON}$, but there was no significant change after the training. It has been reported that PDs have shown increased muscular fatigue and decreased muscular strength, both of which could affect the muscular action required by the timed up and go test. It may be that our version of Tai chi does not improve lower extremity power substantially. The experiments presented here show that the functional forward reach ability in the control group worsened significantly during intervention in comparison with those of the TTC exercise. This result confirms the separate observations of previous investigators (Hong et al., 2000; Lan et al., 2002). Palmer et al. (1986) compared the effects of upper body karate training with those of a United Parkinson's Foundation stretching pro- 
gram. They reported that the improvements in both groups were similar. Functional improvement occurred in gait, arm tremor, and coordination, but the function of complex arm-trunk movements was decreased. In the present study, whole body stretching was included in the training protocol. The balance ability was assessed by a single leg stance with eyes opened. The present study showed significantly improved balance ability in the TTC. Balance ability is related to the control of the center of gravity within the base of support. Many persons with PD reported impaired balance and falls (Johnell et al.,1992). Koller and Huber (1989) found that the balance impairment in older adults with a longer duration PD does not usually respond to levodopa, a common treatment drug for PD; 38\% of the persons with PD experience falls; $13 \%$ fall more than once per week; and some studies have reported that PDs fall repeatedly throughout the day. PDs are 5 times more likely than healthy older adults to suffer fall-related injuries, such as hip fractures. Balance capacity and muscle strength are strong risk factors for falling. The present study showed that the PDs who underwent TTC exercise improved their muscle strength and balance capacity, and this will have a positive effect of fall prevention. This improvement, which confirms the separate observations of previous studies, shows that TTC exercise results in better balance capacity, proprioception function, and muscle strength (Canning et al., 1997).

The results of the 6-min walk test did not changed after 12 weeks of TTC exercise. Many of the PDs had poor cardiorespiratory fitness, as evidenced by a lower $\mathrm{VO}_{2 \max }$, but there were several subjects with a normal and even an above-normal fitness level. This study has encouraged increasing interest in cardiorespiratory and gait improvement.

ADL problems are common and debilitating symptoms in PDs. It may increase the burden of living with the disease and also negatively affect all occupational and social activities. The ADL is probably the most appropriate health-related quality of life measure and these dimensions have significant and high correlations with the UPDRS. The present study showed improvement of the TCC group. Herlofson and Larsen's (2003) study showed that the ADL is more related than others with quality of life for PDs. Liu et al. (2005) also showed that Tai chi exercise produce statistically significant improvements in well-being, including significant reductions in mood disturbance, anxiety, stress, tension, depression, anger, fatigue, confusion, and state anxiety.

In conclusion, this study showed that TTC training had good effects on the functional fitness and ADL of PDs. The results suggest that further study of the effects of TTC intervention must be developed in the future.

\section{CONFLICT OF INTEREST}

No potential conflict of interest relevant to this article was reported.

\section{REFERENCES}

American College of Sports Medicine. ACSM's guidelines for exercise testing and prescription. Philadelphia: Lippincott Williams \& Wilkins; 2010.

Burini D, Farabollini B, Iacucci S, Rimatori C, Riccardi G, Capecci M, Provinciali $\mathrm{L}$, Ceravolo MG. A randomised controlled cross-over trial of aerobic training versus Qigong in advanced Parkinson's disease. Eura Medicophys 2006;42:231-238.

Canning CG, Alison JA, Allen NE, Groeller H. Parkinson's disease: an investigation of exercise capacity, respiratory function, and gait. Arch Phys Med Rehabil 1997;78:199-207.

Carlson NR. Foundation of physiological psychology. Boston: Allyn \& Bacon; 2005.

Choi HJ, Garber CE, Jun TW, Jin YS, Chung SJ, Kang HJ. Therapeutic effects of tai chi in patients with Parkinson's disease. ISRN Neurol 2013; 2013:548240.

de Goede CJ, Keus SH, Kwakkel G, Wagenaar RC. The effects of physical therapy in Parkinson's disease: a research synthesis. Arch Phys Med Rehabil 2001;82:509-515.

Ehrt U, Brønnick K, Leentjens AF, Larsen JP, Aarsland D. Depressive symptom profile in Parkinson's disease: a comparison with depression in elderly patients without Parkinson's disease. Int J Geriatr Psychiatry 2006;21:252-258.

Fong SM, Ng GY. The effects on sensorimotor performance and balance with Tai Chi training. Arch Phys Med Rehabil 2006;87:82-87.

Goodwin VA, Richards SH, Taylor RS, Taylor AH, Campbell JL. The effectiveness of exercise interventions for people with Parkinson's disease: a systematic review and meta-analysis. Mov Disord 2008;23:631-640.

Herlofson K, Larsen JP. The influence of fatigue on health-related quality of life in patients with Parkinson's disease. Acta Neurol Scand 2003; 107:1-6.

Hong Y, Li JX, Robinson PD. Balance control, flexibility, and cardiorespiratory fitness among older Tai Chi practitioners. Br J Sports Med 2000; 34:29-34.

Johnell O, Melton LJ 3rd, Atkinson EJ, O'Fallon WM, Kurland LT. Fracture risk in patients with parkinsonism: a population-based study in Olmsted County, Minnesota. Age Ageing 1992;21:32-38. 
Koller WC, Huber SJ. Tremor disorders of aging: diagnosis and management. Geriatrics 1989;44:33-36, 41.

Lan C, Lai JS, Chen SY. Tai Chi Chuan: an ancient wisdom on exercise and health promotion. Sports Med 2002;32:217-224.

Lan C, Lai JS, Wong MK, Yu ML. Cardiorespiratory function, flexibility, and body composition among geriatric Tai Chi Chuan practitioners. Arch Phys Med Rehabil 1996;77:612-616.

Liu Y, Mimura K, Wang L, Ikuta K. Psychological and physiological effects of 24-style taijiquan. Neuropsychobiology 2005;52:212-218.

Palmer SS, Mortimer JA, Webster DD, Bistevins R, Dickinson GL. Exercise therapy for Parkinson's disease. Arch Phys Med Rehabil 1986;67:741745.
Rikli RE, Jones CJ. Development and validation of a functional fitness test for community-residing older adults. J Aging Phys Act 1999;7:129-161.

Tsang WW, Hui-Chan CW. Effect of 4- and 8-wk intensive Tai Chi Training on balance control in the elderly. Med Sci Sports Exerc 2004; 36:648-657.

Xu DQ, Li JX, Hong Y. Effect of regular Tai Chi and jogging exercise on neuromuscular reaction in older people. Age Ageing 2005;34:439-444.

Zhang JG, Ishikawa-Takata K, Yamazaki H, Morita T, Ohta T. The effects of Tai Chi Chuan on physiological function and fear of falling in the less robust elderly: an intervention study for preventing falls. Arch Gerontol Geriatr 2006;42:107-116. 